\title{
Penerapan View board Sebagai Media Informasi Sidang Skripsi Pada PESSTA+ di Perguruan Tinggi
}

\author{
Indri Handayani ${ }^{1}$ \\ Erick Febriyanto $^{2}$ \\ Kevin Rama Putra Sholichin ${ }^{3}$ \\ Dosen STMIK Raharja $^{1,2}$, Mahasiswa STMIK Raharja ${ }^{3}$ \\ E-mail: indri@raharja.info ${ }^{1}$, erick@raharja.info ${ }^{2}$, kevin.rama@ raharja.info ${ }^{3}$
}

\begin{abstract}
ABSTRAK
Informasi merupakan salah satu kunci keberhasilan suatu komunikasi, selain itu informasi juga dapat mempengaruhi proses terjadinya kegiatan komunikasi. Dengan pesatnya kemajuan Ilmu Pendidikan dan Teknologi ditambah dengan mudahnya akses untuk mendapatkan sebuah informasi secara online di zaman yang kian modern ini, maka nilai dari sebuah informasi yang didapatkan haruslah memiliki kualitas, dengan kata lain sebuah informasi haruslah akurat, relevan, tepat waktu dan dapat dipercaya agar dapat membeikan manfaat bagi pengguna nya. PESSTA + (Penilaian Sidang Skripsi dan Tugas Akhir Plus) sebagai media validasi jurnal dan hibah yang dilakukan oleh mahasiswa secara online dan mandiri diharapkan dapat memberikan informasi yang berkualitas dan dapat dipercaya, oleh karena itu, dibutuhkan sarana untuk memberikan solusi, mengevaluasi proses dan memonitoring kinerja proses yang sedang berjalan. Dengan merancang sebuah Viewboard, diharapkan dapat memberikan gambaran informasi mengenai kegiatan sidang skripsi / tugas akhir dari PESSTA +.
\end{abstract}

Kata Kunci - Informasi, PESSTA+ (Penilaian Sidang Skripsi dan Tugas Akhir Plus), Viewboard

\section{ABSTRACT}

Information is a key to the success of a communication, but it also affects the process of communication activities. With the rapid advancement of Science Education and Technology plus the easy access to obtain information online in this increasingly modern era, the value of an information obtained must have quality, in other words an information must be accurate, relevant, timely and reliable in order to benefit the user. PESSTA + (Assessment of Thesis Sessions and Final Task Plus) as a medium of validation of journals and grants conducted by students online and independent is expected to provide reliable and qualified information, therefore, a tool is needed to provide solutions, evaluate processes and monitor performance processes that are running. By designing a Viewboard, it is expected to provide an overview of the thesis session / end task activities of PESSTA +.

Keywords - Information, PESSTA+ (Penilaian Sidang Skripsi dan Tugas Akhir Plus), Viewboard 


\section{PENDAHULUAN}

PESSTA+ (Penilaian Sidang Skripsi dan Tugas Akhir Plus) adalah sebuah sistem online berupa website mengenai validasi jurnal dan hibah yang dilakukan oleh mahasiswa di Perguruan Tinggi Raharja. Di zaman modern ini peranan informasi sangatlah penting karena dapat mempengaruhi proses terjadinya kegiatan komunikasi, informasi pun dapat disampaikan dengan mudah melalui beberapa media, diantaranya media elektronik maupun media cetak, ditambah dengan kemajuan teknologi informasi yang semakin pesat yang diharapkan dapat memberikan manfaat bagi masyarakat sebagai salah satu upaya mewujudkan masyarakat berbasis informasi dan teknologi.

Perguruan Tinggi Raharja merupakan salah satu instansi pendidikan yang memiliki konsentrasi di bidang komputer dan teknologi informasi, oleh karena itu Perguruan Tinggi Raharja senantiasa selalu berinovasi dalam menciptakan sistem - sistem yang dapat membantu kegiatan perkuliahan maupun kemasyarakatan. Dalam sebuah sistem perlu adanya bukti ataupun data yang valid agar dapat menampilkan informasi mengenai kinerja institusional kepada institusi maupun khalayak. Oleh karena itu, sebuah Viewboard atau Dashboard sangatlah dibutuhkan.

Menurut Kusnami (2009), Dashboard adalah satu kategori dari aplikasi business intelligence yang secara real time akan memonitoring berbagai informasi yang dibutuhkan oleh suatu organisasi atau perusahaan dengan berbagai macam format seperti graphical gadgets, typically, gauges, charts, indicators, dan color - coded maps yang memungkinkan mereka membuat keputusan pintar secara cepat.[1]

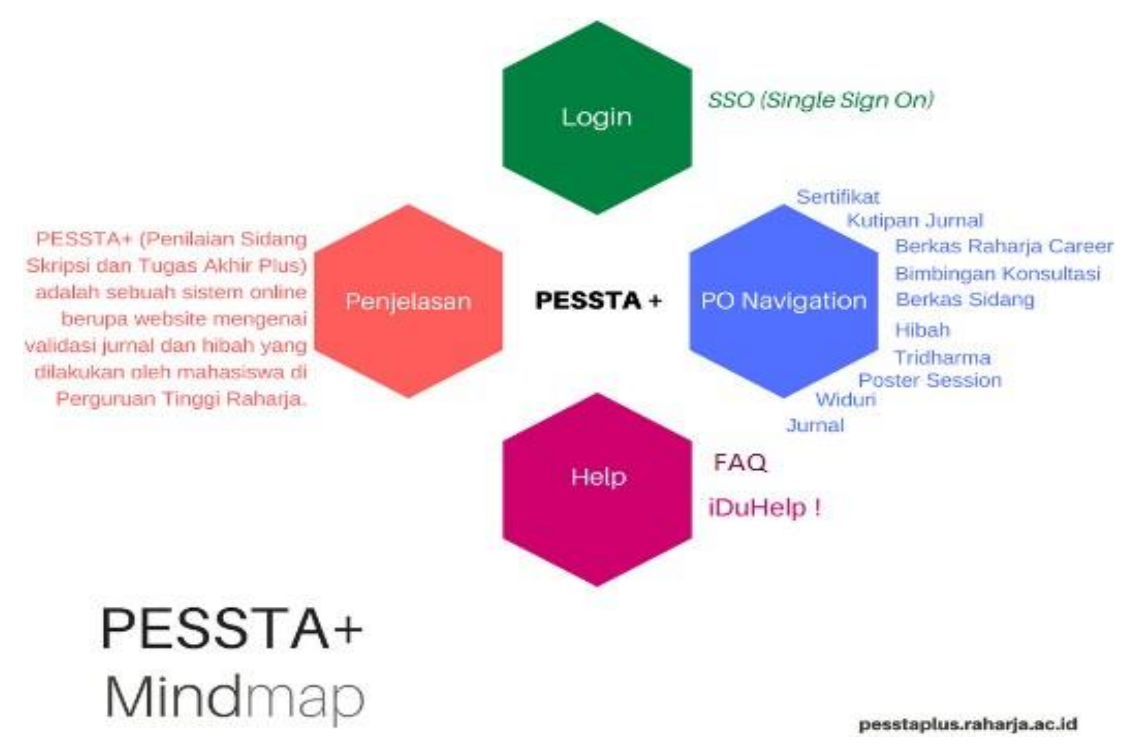

Gambar 1. Mind Mapping PESSTA+

Gambar diatas menjelaskan tentang Mind Mapping website PESSTA+, yang terdiri dari : Login, menggunakan SSO (Single Sign On) dengan Rinfo, PO Navigation, yaitu berisi menu input untuk submit sertifikat, kutipan jurnal, berkas raharja career, bimbingan konsultasi, berkas sidang, hibah, tridharma, poster session, widuri dan jurnal, Help, yaitu berisi menu mengenai FAQ dan button iDuHelp !, Penjelasan mengenai PESSTA+, yaitu sebuah sistem online berupa 
website mengenai validasi jurnal dan hibah yang dilakukan oleh mahasiswa di Perguruan Tinggi Raharja.

\section{METODE PENELITIAN}

Dalam sebuah proses penulisan karya ilmiah dibutuhkan adanya metode penelitian yang berguna untuk mencapai tujuan dan mendapatkan informasi yang akurat dan terpercaya yang dibutuhkan oleh penulis untuk melakukan beberapa tahapan dalam penelitian. Dalam pembuatan Viewboard atau Dashboard, terdapat 7 tahapan metode yang sesuai dengan tahapan pengembangan sistem perangkat lunak, diantaranya yaitu identifikasi kebutuhan, perencanaan, perancangan prototype, review prototype, implementasi, deployment dan maintenance. Namun dalam penelitian ini hanya akan menggunakan 4 tahapan, yaitu identifikasi masalah, perencanaan, perancangan prototype dan review prototype. Berikut perancangan metode penelitian yang digunakan.

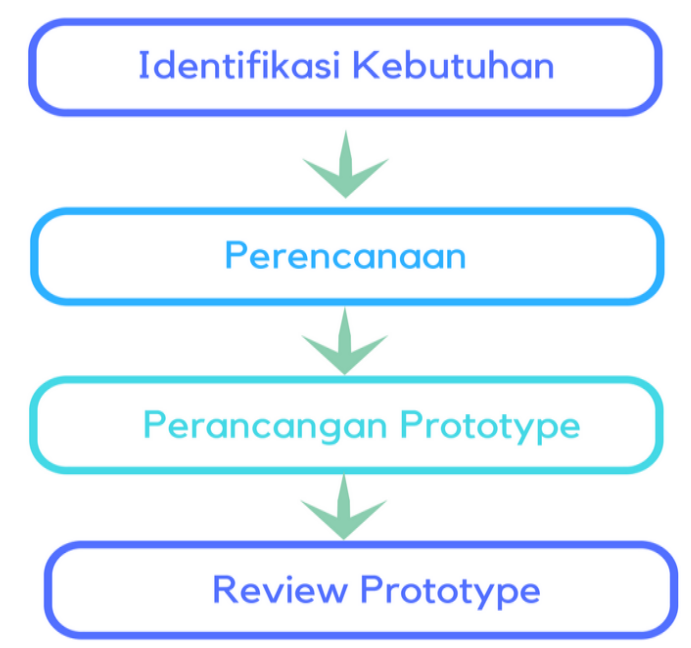

Gambar 2. Tahapan Penelitian

Identifikasi Kebutuhan, melakukan pendekatan secara top-down untuk mendapatkan gambaran mengenai skenario informasi yang akan disajikan pada viewboard atau Dashboard. Perencanaan, menganalisis data yang telah diperoleh dari hasil identifikasi kebutuhan lalu Perancangan Prototype, untuk melihat kesesuaian antara kebutuhan pengguna dengan sistem yang sudah direncanakan sebelum diimplementasikan secara nyata dan Review Prototype, untuk melakukan perbaikan sistem jika ada ketidaksesuaian dengan kebutuhan pengguna. Berikut ini adalah daftar literature review yang digunakan dalam penelitian ini:

1. Penelitian yang dilakukan oleh Danang Yuli Setiawan, Rully Agus Hendrawan dan Raras Tyasnurita dengan judul "Perancangan Business Intelligence Dashboard Berbasis Web Untuk Pemantauan Tingkat Keberhasilan Pambangunan Ketenagakerjaan (Studi Kasus: Provinsi Jawa Timur)" Pada penelitian ini membahas tentang perancangan BI Dashboard yang tepat sehingga dapat diimplementasikan oleh Disnakertansduk Jawa Timur guna mendukung proses evaluasi dan perencanaan tenaga kerja yang 
handal/reliabel

2. Penelitian yang dilakukan oleh Eva Hariyanti, Indah Werdiningsi dan Kridanto Surendro dengan judul yaitu "Model Pengembangan Dashboard Untuk Monitoring dan Evaluasi Kinerja Perguruan Tinggi" Pada penelitian ini membahas tentang perancangan model pengembangan dashboard untuk kebutuhan perguruan tinggi. Model yang dihasilkan digunakan untuk pengembangan dashboard bagi kebutuhan monitoring dan evaluasi kinerja perguruan tinggi.

3. Penelitian yang dilakukan oleh Ilhamsyah dan Syahru Rahmayuda dengan judul yaitu "Perancangan Model Dashboard Untuk Monitoring Evaluasi Mahasiswa" Pada penelitian ini membahas tentang penggunaan dashboard sebagai sistem monitoring evaluasi mahasiswa di bidang pendidikan di Jurusan Sistem Informasi FMIPA Universitas Tanjungpura Pontianak.

4. Penelitian yang dilakukan oleh Untung Rahardja, Oleh Sholeh, Fitria Nursetianingsih dengan judul yaitu "Penggunaan Dashboard Untuk Mengontrol Kinerja Absensi Pegawai Pada PT. Sinarmas Land Property". Pada penelitian ini membahas tentang penggunaan dashboard yang menyajikan informasi kedisiplinan absensi pegawai dapat digunakan untuk pengambilan keputusan perusahaan untuk mempertimbangkan dalam mempertahankan pegawainya untuk melakukan kerja sama demi tercapainya keberhasilan bisnis perusaan. Data yang ditampilkan dalam dashboard berbentuk grafik interaktif sehingga dari grafik tersebut perusahaan dapat mengetahui performa absensi dari para pegawainya.

5. Penelitian yang dilakukan oleh Dini Nurmalasari, Retro Tri Wahyuni, Yusmar Palapa dengan judul yaitu "Informational Dashboard untuk Monitoring Sistem Drainase secara Real-Time". Pada penelitian ini membahas tentang sistem pengelolaan dan proses monitoring saluran drainase yang masih dilakukan secara manual dirasa belum bekerja dengan baik karena masih terdapat kekurangan sehingga perlu adanya aplikasi monitoring berbasis web yang didukung dengan informational dashboard yang dapat memberikan data dan informasi yang akurat mengenai kondisi dari drainase secara efektif dan efisien.

6. Penelitian yang dilakukan oleh Agus Prasetyo Utomo, Melly Putri Damayanti, Deni Multazam dengan judul yaitu "Perancangan Dashboard Untuk Sistem Informasi Monitoring dan Evaluasi Prestasi Siswa SMA Berbasis Kurikulum 2013”. Pada penelitian ini membahas tentang sistem informasi monitoring dan evaluasi dalam prestasi siswa yang dibuat untuk membantu kepala sekolah dan guru dalam mengevaluasi dan memonitor penilaian hasil dari studi siswa SMA sesuai dengan Kurikulum Nasional 2013. Sistem yang dikembangkan menggunakan konsep dashboard untuk media penyajian informasi dengan menggunakan visualisasi dalam bentuk grafik.

7. Penelitian yang dilakukan oleh Fandi Cahyo Saputro, Wiwik Anggraeni dan Ahmad Mukhlason dengan judul yaitu "Pembuatan Dashboard Berbasis Web Sebagai Sarana Evaluasi Diri Berkala untuk Persiapan Penilaian Akreditasi Berdasarkan Standar Badan Akreditasi Nasional Perguruan Tinggi”. Pada penelitian ini membahas tentang evaluasi diri secara berkala dengan menggunakan sarana Dashboard untuk memenuhi standar yang ditetapkan oleh BAN-PT yang merupakan parameter untuk menentukan mutu 
perguruan tinggi.

8. Penelitian yang dilakukan oleh Untung Rahardja, Indri Handayani dan Lilis Setiani dengan judul yaitu "Penerapan Viewboard Sebagai Media Informasi Jumlah Artikel Pada iLearning Raharja Ask and News". Pada penelitian ini membahas tentang perancangan sistem viewboard atau dashboard untuk menampilkan informasi mengenai jumlah artikel pada iLearning Raharja Ask and News.

\section{HASIL DAN PEMBAHASAN}

\subsection{Analisa Permas alahan}

Dengan adanya kemajuan teknologi yang sangat pesat, siapapun dapat dengan mudah memperoleh sebuah informasi dari berbagai sumber, termasuk melalui media online. Dikarenakan besarnya kebutuhan akan informasi, saat ini banyak official site di bidang perdagangan, kelembagaan maupun di bidang pendidikan, dalam bidang pendidikan, banyak official site yang memberikan informasi seputar lembaga pendidikan yang dapat diakses oleh public. PESSTA+ merupakan salah satu official site online yang dimiliki oleh Perguruan Tinggi Raharja yang dapat memberikan informasi seputar validasi jurnal dan hibah mahasiswa kapanpun dan dimanapun. Karena keterbatasan fitur dan sistem yang ada, setiap informasi mengenai validasi jurnal dan hibah mahasiswa hanya bisa diakses oleh Pribadi Raharja saja, jadi pengunjung Non Pribadi Raharja tidak bisa mengakses informasi mengenai validasi jurnal dan hibah mahasiswa. Saat ini belum adanya fitur sistem mengenai informasi jurnal dan hibah mahasiswa yang bisa diakses secara publik atau Non Pribadi Raharja.

Dengan adanya permasalahan tersebut dalam kemudahan memberikan informasi, maka rumusan masalah dalam penelitian ini adalah bagaimana merancang sebuah sistem informasi yang dapat menampilkan informasi seputar validasi jurnal dan hibah mahasiswa yang dapat diakses secara public atau bagi Non Pribadi Raharja dalam PESSTA+ pada Perguruan Tinggi Raharja.

\subsection{Pemecahan Masalah}

Untuk mengatasi permasalahan yang telah dijabarkan di atas, maka diperlukan sebuah sisem yang dapat menampilkan informasi seputar validasi jurnal dan hibah mahasiswa yang bisa diakses secara public, salah satu media yang dapat digunakan yaitu Data Table, dengan menggunakan Data Table ini memungkinkan untuk menghubungkan database dengan table menggunakan bahasa pemrograman PHP, dan menambahkan menu tersendiri pada halaman utama PESSTA+ menuju Data Table yang dibuat. Sehingga kita dapat menampilkan informasi mengenai validasi jurnal dan hibah tanpa harus login terlebih dahulu.

Data Table merupakan sebuah table yang berisi data yang dihubungkan ke Database, Data Table dapat dibuat dengan bahasa pemrograman HTML maupun bahasa pemrograman PHP.

\subsection{Listing Program}

Viewboard atau Dashboard digunakan sebagai alat untuk menyajikan informasi secara sekilas, solusi bagi kebutuhan informasi sebuah organisasi. Dengan 
memanfaatkan Data Table, dapat menampilkan informasi keseluruhan informasi mengenai validasi jurnal dan hibah mahasiswa. Berikut listing programnya :

$<$ table border $=1>$

<table class="table table-bordered table-striped">

$<$ tr $>$

$\langle\mathrm{td}\rangle\langle\mathrm{b}\rangle \mathrm{No}</ \mathrm{td}\rangle$

$\langle\mathrm{td}\rangle\langle\mathrm{b}\rangle \mathrm{NIM}</ \mathrm{td}\rangle$

$\langle\mathrm{td}\rangle\langle\mathrm{b}\rangle$ Mahasiswa $</ \mathrm{td}\rangle$

$<\mathrm{td}\rangle\langle\mathrm{b}>$ Pembimbing $1</ \mathrm{td}>$

$\langle\mathrm{td}\rangle\langle\mathrm{b}>$ Pembimbing $2</ \mathrm{td}\rangle$

$\langle\mathrm{td}\rangle\langle\mathrm{b}>\mathrm{PO} 1</ \mathrm{td}\rangle$

$\langle\mathrm{td}\rangle\langle\mathrm{b}\rangle \mathrm{PO} 2</ \mathrm{td}\rangle$

$\langle\mathrm{td}\rangle\langle\mathrm{b}\rangle \mathrm{PO} 3</ \mathrm{td}\rangle$

$\langle\mathrm{td}\rangle\langle\mathrm{b}\rangle \mathrm{PO} 4</ \mathrm{td}\rangle$

$\langle\mathrm{td}\rangle\langle\mathrm{b}\rangle$ PO $5</ \mathrm{td}\rangle$

$\langle\mathrm{td}\rangle\langle\mathrm{b}\rangle \mathrm{PO} 6</ \mathrm{td}\rangle$

$\langle\mathrm{td}\rangle\langle\mathrm{b}>\mathrm{PO} 7</ \mathrm{td}\rangle$

$\langle\mathrm{td}\rangle\langle\mathrm{b}>\mathrm{PO} 8</ \mathrm{td}\rangle$

$\langle\mathrm{td}\rangle\langle\mathrm{b}>\mathrm{PO} 9</ \mathrm{td}>$

$\langle\mathrm{td}\rangle\langle\mathrm{b}>\mathrm{PO} 10</ \mathrm{td}\rangle$

$</ \operatorname{tr}\rangle$

$<$ ?php

$\$$ no $=1$;

foreach (Yii::\$app->PembC->pemb_tampilmahasiswa() as \$data) \{ ?>

$<$ tr $>$

$<\mathrm{td}><$ ?php echo $\$$ no ; ? $></ \mathrm{td}>$

$<\mathrm{td}><$ a href="<?php echo Yii::\$app->urlManager-

$>$ createUrl(array_merge(['/input/nilai'],['nim'=> \$data['Nim']])); ?> "><?php

echo \$data['Nim'] ? $></ \mathrm{a}\rangle\langle/ \mathrm{td}\rangle$

$<\mathrm{td}><$ ?php echo \$data['Nama'] ? $></ \mathrm{td}>$

$\langle$ td $\rangle\langle$ ?php echo \$data['NamaDosen1'] ? $>\langle/$ td $\rangle$

$\langle$ td $\rangle<$ ?php echo \$data['NamaDosen2'] ? $></$ td $>$

$\langle\mathrm{td}\rangle\langle$ ?php echo \$data['StatusSubmit1'] ? $></ \mathrm{td}\rangle$

$\langle\mathrm{td}\rangle<$ ?php echo \$data['StatusSubmit2'] ? $></ \mathrm{td}\rangle$

$<\mathrm{td}><$ ?php echo \$data['StatusSubmit3'] ? $></ \mathrm{td}>$

60 | Indri, Erick, Kevin - Penerapan Viewboard Sebagai Media Informasi... 


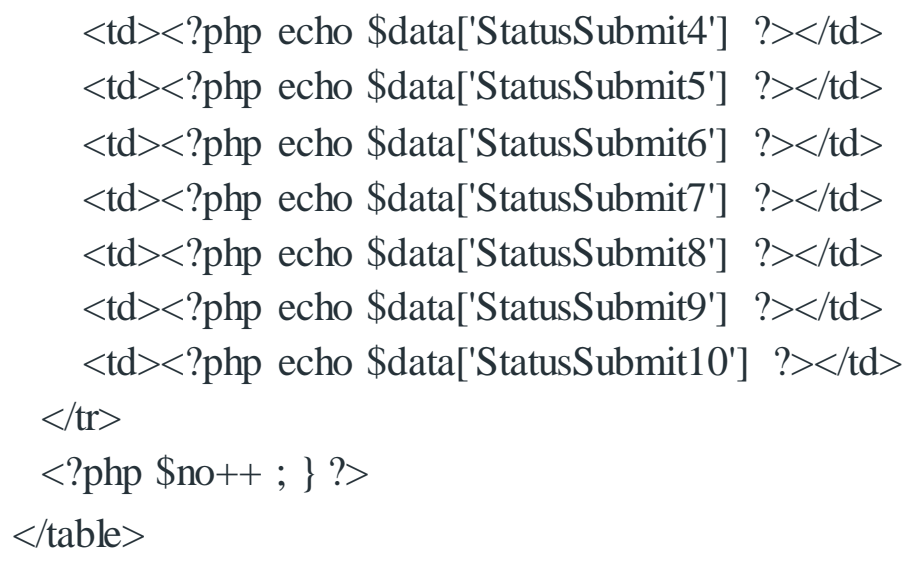

\subsection{Implementasi}

Viewboard atau Dashboard yang telah dibuat dengan Data Table akan diimplementasikan sebagai media informasi mengenai validasi jurnal dan hibah mahasiswa yang dapat dengan mudah dan dipahami oleh Public. Berikut cara mengimplementasikan Viewboard atau Dashboard pada PESSTA+:

1. Buka aplikasi pengolah code (IDE), dalam kasus ini saya menggunakan Codeanywhere.

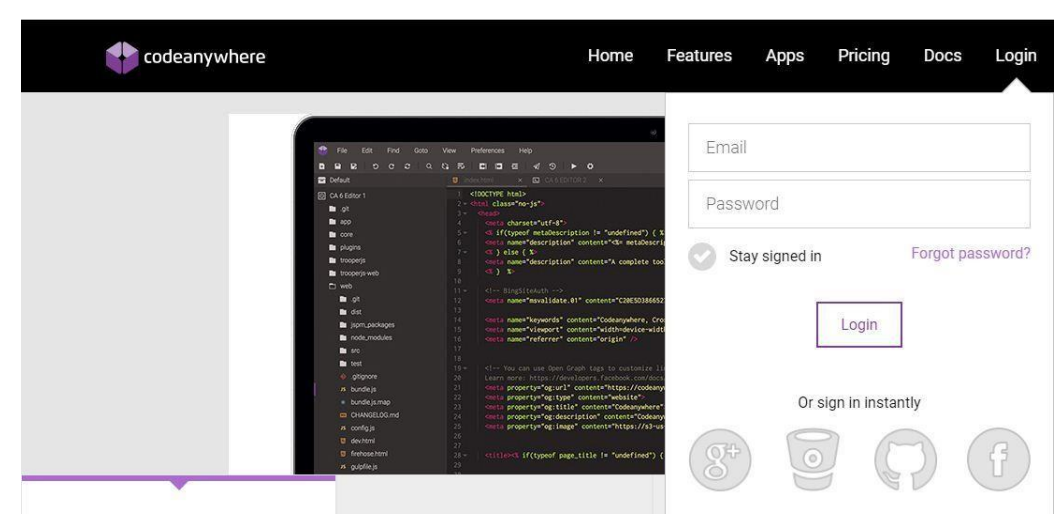

Gambar 6. Tampilan Login Codeanywhere

Gambar diatas merupakan halaman login yang terdapat pada Codeanywhere.com.

2. Copy script Data Table ke dalam Codeanywhere.

$<$ table border $=1>$

$<$ table class="table table-bordered table-striped">

$<\operatorname{tr}\rangle$

$\langle\mathrm{td}\rangle\langle\mathrm{b}\rangle \mathrm{No}</ \mathrm{td}\rangle$

$\langle\mathrm{td}\rangle\langle\mathrm{b}\rangle \mathrm{NIM}</ \mathrm{td}\rangle$

61 | Indri, Erick, Kevin-Penerapan Viewboard Sebagai Media Informasi... 


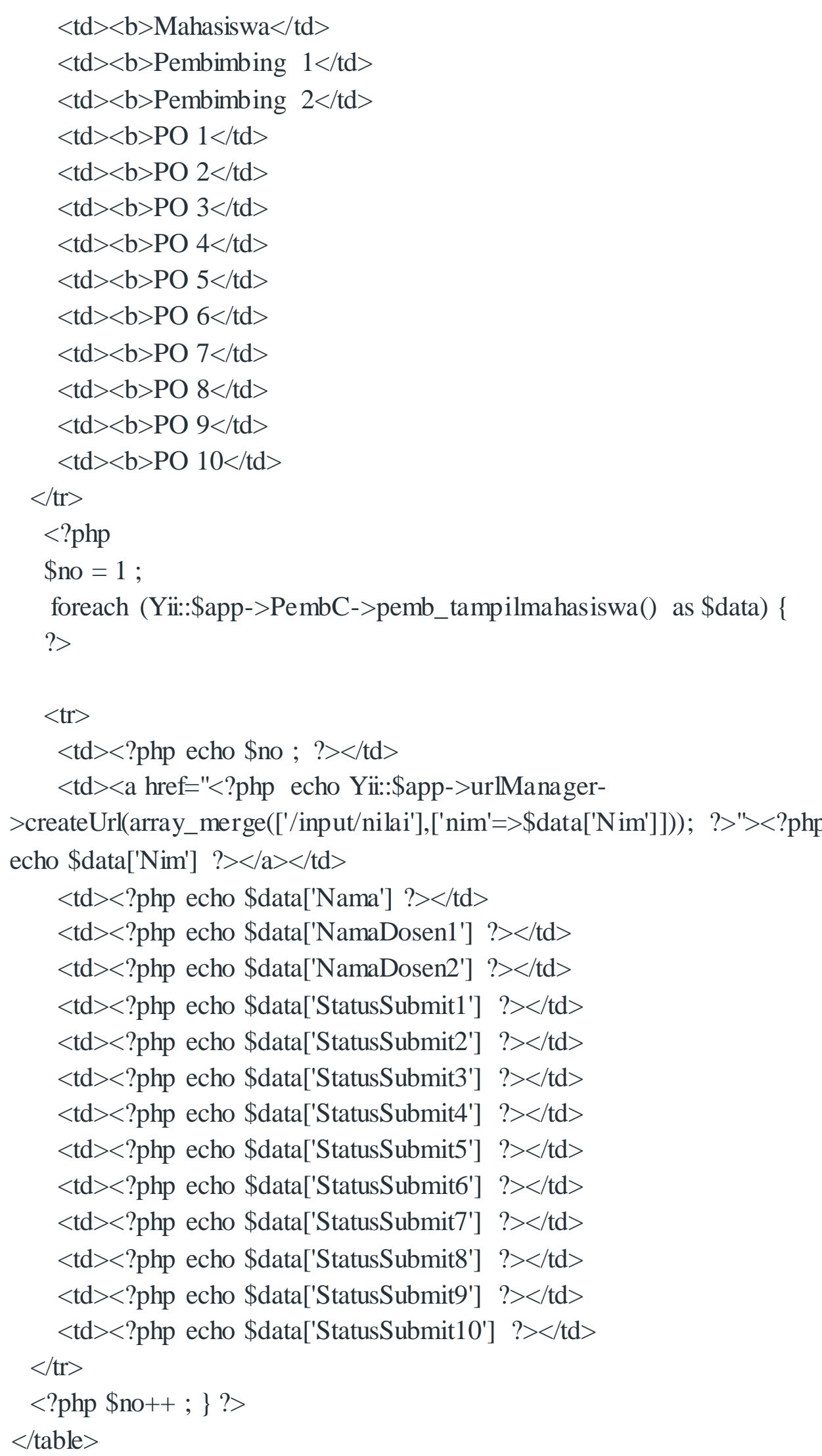

62 | Indri, Erick, Kevin-Penerapan Viewboard Sebagai Media Informasi... 
3. Lalu save di Codeanywhere.

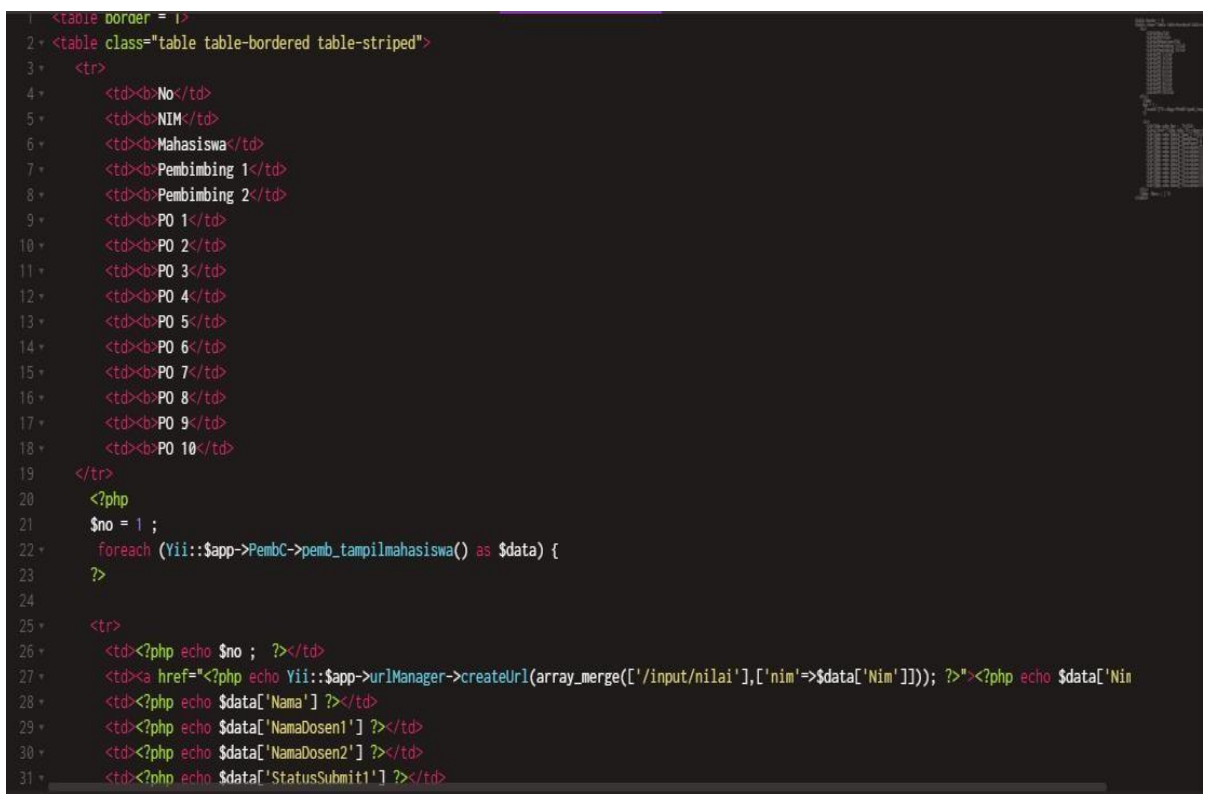

Gambar 7. Script Data Table pada Codeanywhere

Gambar diatas merupakan Workspace dari Codeanywhere yang telah dihubungkan dengan server PESSTA+.

4. Viewboard berhasil dimasukkan ke dalam menu PESSTA+. Untuk melihat viewboard PESSTA+ kunjungi http//pesstaplus.raharja.ac.id/ dan klik pada menu Viewboard PESSTA+. Berikut tampilannya.

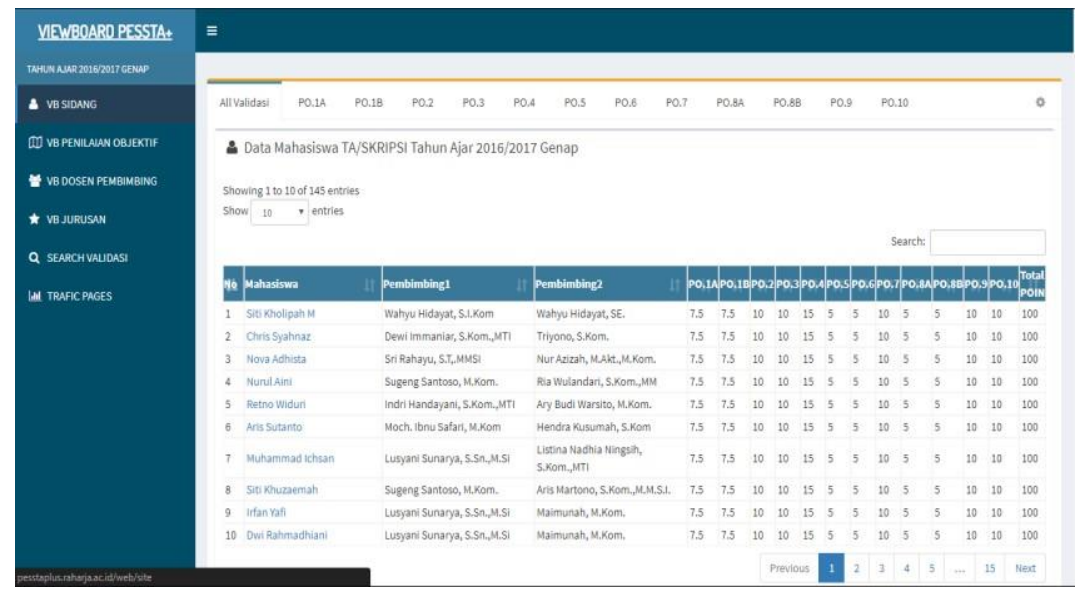

Gambar 8. Tampilan Viewboard PESSTA+

63 | Indri, Erick, Kevin-Penerapan Viewboard Sebagai Media Informasi... 
Gambar diatas merupakan tampilan viewboard atau dashboard yang telah di implementasikan kedalam sistem PESSTA+.

\section{KESIMPULAN}

Kesimpulan dari sistem yang telah dibuat dan telah sesuai dengan apa yang ingin ditampilkan, dapat ditarik kesimpulan bahwa dengan adanya viewboard atau dashboard dapat memberikan informasi yang efektif dan efisien karena :

1. Viewboard atau Dashboard dapat menggambarkan informasi secara mendetail dan mudah dipahami.

2. Viewboard atau Dashboard yang telah dibuat dengan baik dapat memberikan informasi yang efektif dan efisien mengenai validasi jurnal dan hibah mahasiswa.

3. Dengan adanya viewboard atau Dashboard ini, pengunjung dapat lebih mudah mendapatkan informasi mengenai validasi jurnal dan hibah tanpa harus login terlebih dahulu.

\section{SARAN}

Berdasarkan dari pembahasan yang telah dijabarkan sebelumnya, penulis dapat menyimpulkan saran sebagai berikut :

1. Perlu adanya pengembangan yang lebih untuk viewboard atau dashboard PESSTA+ agar dapat memuat lebih banyak informasi selain validasi jurnal dan hibah mahasiswa

2. Viewboard atau dashboard PESSTA+ dapat dikembangkan lebih lanjut untuk dapat menyajikan informasi yang mudah dimengerti bagi masyarakat awam.

3. Viewboard atau dashboard dapat dijadikan bahan sebagai evaluasi dari sebuah institusional.

\section{DAFTAR PUSTAKA}

[1] Kusnami. (2009). Aplikasi Data Warehouse Untuk Business Inteligence. Jakarta: Gramedia.

[2] Danang Yuli Setiawan, Rully Agus Hendrawan, Raras Tyasnurita. 2013. "Perancangan Business Intelligence Dashboard Berbasis Web Untuk Pemantauan Tingkat Keberhasilan Pambangunan Ketenagakerjaan (Studi Kasus: Provinsi Jawa Timur)”. JURNAL TEKNIK POMITS Vol. 2, No. 1, (2013). ISSN : 2337-3539

[3] Eva Hariyanti, Indah Werdiningsih, Kridanto Surendro. 2011. "Model Pengembangan Dashboard Untuk Monitoring dan Evaluasi Kinerja Perguruan Tinggi”. JUTI, Vol. 9 No. 1

[4] Ilhamsyah, Syahru Rahmayuda. 2017. "Perancangan Model Dashboard Untuk Monitoring Evaluasi Mahasiswa”. Jurnal Informatika:Jurnal Pengembangan IT (JPIT) , Vol. 2, No. 1, ISSN : 2477-5126.

[5] Untung Rahardja, Oleh Sholeh, Fitria Nursetianingsih. 2015. “Penggunaan Dashboard Untuk Mengontrol Kinerja Absensi Pegawai Guna Meningkatkan Profesionalisme Pegawai Pada PT. Sinarmas Land Property". ISSN : 2302-3805.

[6] Dini Nurmalasari, Retro Tri Wahyuni, Yusmar Palapa. 2015. "Informational Dashboard untuk Monitoring Sistem Drainase secara Real-Time”. JNTETI, Vol. 4, No. 3

64 | Indri, Erick, Kevin-Penerapan Viewboard Sebagai Media Informasi... 
[7] Agus_Prasetyo_Utomo, M. (2016). PERANCANGAN DASHBORD UNTUK SISTEM INFORMASI MONITORING DAN EVALUASI PRESTASI SISWA SMA BERBASIS KURIKULUM 2013. e-BISNIS, 9(1), 24-31.

[8] Fandi Cahyo Saputro, Wiwik Anggraeni dan Ahmad Mukhlason. 2012. "Pembuatan Dashboard Berbasis Web Sebagai Sarana Evaluasi Diri Berkala untuk Persiapan Penilaian Akreditasi Berdasarkan Standar Badan Akreditasi Nasional Perguruan Tinggi”. JURNAL TEKNIK ITS Vol. 1, ISSN: 2301-9271

[9] Rahardja, U., Handayani, I., \& Setiani, L. (2017). Viewboard Sebagai Laporan Jumlah Keseluruhan Artikel Pada iLearning Raharja Ask and News. CogITo Smart Journal, 3(1), 42-55. 